\title{
THE GASTROPTERIDAE OF GUAM, WITH DESCRIPTIONS OF FOUR NEW SPECIES (OPISTHOBRANCHIA :CEPHALASPIDEA)
}

\author{
$\operatorname{AUTHOR}(\mathrm{S}):$ \\ Carlson, C. H.; Hoff, P. J.
}

\section{CITATION:}

Carlson, C. H. ...[et al]. THE GASTROPTERIDAE OF GUAM, WITH DESCRIPTIONS OF FOUR NEW SPECIES (OPISTHOBRANCHIA : CEPHALASPIDEA). PUBLICATIONS OF THE SETO MARINE BIOLOGICAL LABORATORY 1974, 21(5-6): 345-363

ISSUE DATE:

1974-12-23

URL:

http://hdl.handle.net/2433/175876

RIGHT: 


\title{
THE GASTROPTERIDAE OF GUAM, WITH DESCRIPTIONS OF FOUR NEW SPECIES (OPISTHOBRANCHIA : CEPHALASPIDEA) ${ }^{1)}$
}

\author{
C. H. CARLSON and P. J. HOFF \\ The Marine Laboratory, University of Guam, Agana, Guam 96910
}

With Text-figures $1-13$ and Plate $X$

From 1969 to the present the authors have maintained a regular log of the opisthobranchs seen on Guam. Most of the study has been done in the area of Bile Bay, near the village of Merizo. During this time over a thousand specimens of Gastropteridae, representing seven species, have been observed. Only a few of each species were collected, external descriptions were made, and color photograph slides taken. Until recently no effort was made by the authors to describe these animals.

Gastropteridae are cephalaspid animals with paired parapodia which extend up over the dorsum, an elongate tapered tail, a posterior funnel on the cephalic shield, and a relatively short free mantle margin on the right side with the ctenidium usually located just below the mantle margin. In 1964 Tokioka and Baba divided the Gastropteridae into two genera: Gastropteron characterized by a radular formula of 4-6, 1. 0 . 1. 4-6 and with denticulations on the inner edge of the main hook of the first lateral; Sagaminopteron characterized by a radular formula of 9-12,1,0.1.9-12, with two prominent cusps on the inner edge of the main hook of the first lateral. Carlson and Hoff (1973) described two new species of Sagaminopteron which had fewer marginals than the radular formula given by Tokioka and $\mathrm{Baba}$, but the marginals were still more numerous than in Gastropteron. In 1967 a third genus, Enotepteron, was established by Minichev for a species collected near Tsingtao in the Yellow Sea. Enotepteron has four prominent cusps on the inner edge of the first lateral and a radular formula of 3. 1.0.1.3. Only two of the genera, Gastropteron and Sagaminopteron, have been found on Guam.

All external descriptions and comparative measurements presented here are from living animals. Since Gastropteridae change shape as they move, all such comparisons should be considered relative.

Specimens of new species described in this paper are deposited in the Bernice P.

1) Contribution No. 57 from the University of Guam Marine Laboratory.

Publ. Seto Mar. Biol. Lab., XXI (5/6), 345-363, 1974 . (Article 22) 
Bishop Museum, Honolulu, Hawaii, and the Field Museum of Natural History, Chicago, Illinois.

\section{Genus Gastropteron}

Of the four species of Gastropteron found on Guam, only one has been previously described.

\section{Gastropteron flavum Tokioka and Baba}

(Text-figs. 12. e, 13. a)

References: Tokioka and Baba 1964, pp. 12-15, Text-figs. 5-7, Pl. X figs. 10-12, Pl. XI figs. 6-8, Pl. XIII fig. 3. Tokioka and Baba 1965, pp. 40-41, Text-fig. 7, D.

Since. August, 1969, numerous specimens of G. flavum have been observed on Guam, as well as on other islands of the Mariana chain, Palau, and Truk. Although the general body shape and radula are basically the same there are several variations in color.

The first animals mentioned by Tokioka and Baba (1964) were described as bright yellow, minutely dotted with white. The posterior of the cephalic shield was ivory black, as was the dorso-median crest and the projection ${ }^{2)}$ on the dorsal hump. Another specimen described by the same authors (Baba and Tokioka, 1965) was yellow, dotted with yellow and had reddish purple on the posterior margins of the funnel, on the dorso-median crest, and on the protuberance. There was an additional reddish purple spot on the posterior of the dorsal hump.

G. flavum is one of the most common opisthobranchs found on Guam, more than 600 specimens having been observed. Most of the animals were found in very shallow water, but some have been seen in depths of up to twelve meters. To the naked eye these animals appear yellow with black markings. Through the microscope they are yellow with large white spots scattered over the dorsum and parapodia. The parapodia are lined with dark brown as is the back edge of the funnel. The dorso-median crest and the protuberance are tipped in black.

Although the number of marginals in the radula differ slightly from the Japanese animals, the shape of the teeth is the same. The Guam animals studied had small radulae (Text-fig. 13. a.), that of a $3.5 \mathrm{~mm}$ animal being $0.25 \mathrm{~mm}$ in length, with radular formulas of 18-20. X 3.1.0.1.3. G. flavum described by Tokioka and Baba (1964) had a formula of $22 \times 4.1 .0 .1 .4$. The free mantle margin is extremely short. The ctenidium on the Guam animals is normally very small, being made up of a triangulate leaflet.

2) The term 'flagellar appendage' is used for any posterior protuberance of the dorsal hump which is an extension of the free mantle margin. 'Projection' is used when the posterior protuberance is not an extension of the free mantle margin. 
Nine specimens from 3.0 to $9.0 \mathrm{~mm}$ were observed at the Mariana Islands of Agrihan, Asuncion, Maug, and Uracas in 1972. These animals did not have the parapodia lined in brown but rather had one small area of brown just posterior to the highest part of the parapodia. There were also two brown spots just behind the cephalic shield and the dorsal protuberance was brown. The radular formula from one $6.0 \mathrm{~mm}$ specimen was $17 \times 3.1 .0 .1 .3$. The shape of the teeth matches G. flavum from Japan.

Three $3.0 \mathrm{~mm}$ specimens were observed in Apaan Bay, Pagan, Mariana Islands in 1971 with the same markings as the Guam animals. Two specimens containing the same markings as the Guam animals were observed near Koror, Palau, Western Caroline Islands, in 1969 . One $3.5 \mathrm{~mm}$ specimen was observed on Moen, Truk, in the Eastern Caroline Islands in 1973. This animal had the same brown markings as the Guam animals but the base color was pink rather than yellow.

REMARKS: G. flavum is normally found under or on the sides of rocks and coral rubble. During the season when Caulerpa racemosa is on the reef flats, it may also be found in this algae. During the months of August through October, 1973 (when this article was completed) G. flavum was rarely seen. This could possibly be attributed to unusually low tide conditions during October, 1972, which may have destroyed the egg masses on the reef flats. The reef flats during that time were without water for several days at a time so that nearly all animals and plants on the reef flat were killed.

A microscopic bivalve was found inside one specimen of G. flavum.

\section{Gastropteron brunneomarginatum n. sp.}

(Text-figs. 1, 2, 12. c, 13. b; Pl. X, fig. 1)

DESCRIPTION: Only five specimens have been collected on Guam since September, 1970. The animals found have varied from 3.9 to $5.5 \mathrm{~mm}$ in length, the average being about $4.0 \mathrm{~mm}$ in length.

G. brunneomarginatum has a very narrow and long, slightly indented anteriorly, cephalic shield (Text-fig. 1;C. s.). The cephalic shield tapers only slightly toward the posterior and forms a funnel (Text-fig. $1 ;$ F.) which projects forward but does not extend beyond the front of the shield when the animal is crawling. With the funnel projecting upward the cephalic shield was $1.5 \mathrm{~mm}$ long on a $5.5 \mathrm{~mm}$ animal. The dorso-median crest (Text-fig. 1 ; M. c.) projects slightly beyond the edge of the funnel. Since the funnel does not close completely posteriorly, the dorso-median crest is easily visible. The eye spots are faintly visible through the integument at the anterior base of the funnel.

The dorsal hump (Text-fig. 1 ; D. h.) is long, narrow, smooth, and rounded. There is a clear division between the dorsal hump and the tail with the ventral part joining the tail about one third of the way from the anterior of the dorsal hump (see stylized 
drawing, Text-fig. 11). There is a bulge to the right posterior on a few specimens. On a $5.5 \mathrm{~mm}$ animal the dorsal hump is $3.5 \mathrm{~mm}$ long, and the entire animal is $1.5 \mathrm{~mm}$ wide with parapodia (Text-figs. 1, 2;P.) in their normal raised position. The free mantle margin (Text-fig. $2 ; \mathrm{M} . \mathrm{m}$.) is very long for a Gastropteron. It extends from the anterior of the dorsal hump back to a flattened flagellar appendage (Text-figs. 1, $2 ;$ F. a.) which projects posteriorly. The mantle margin is very narrow, basically a thickened part of the epidermis, widening only slightly to the posterior.

The ctenidium (Text-fig. 2 ; C.) is concealed by the parapodia and is not visible when the animal is crawling. The ctenidium is made up of a triangular plate with 6

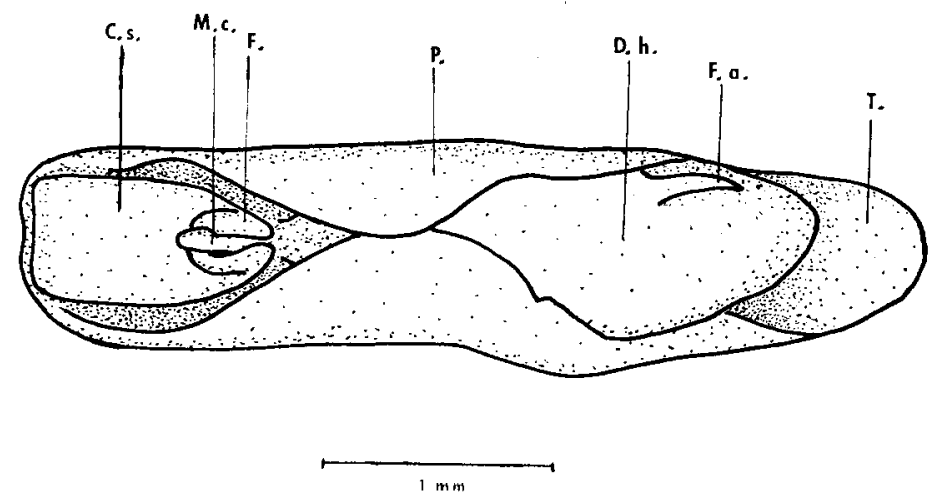

Text-fig. 1. Gastropteron brunneomarginatum n. sp. Dorsal view. For abbreviations, see p. 361 .

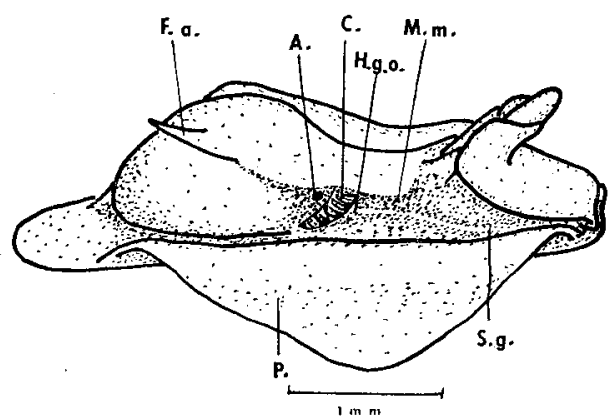

Text-fig. 2. Gastropteron brunneomarginatum n. sp. Right side view.

or 7 small leaflets attached their entire length to the plate. The narrow side of the triangular plate is attached ventral to and about half way back on the free mantle margin. The anus (Text-fig. 2 ;A.) is just posterior to the gill. The seminal groove (Text-fig. $2 ;$ S. g.) slants downward from the hermaphroditic genital orifice (Text-fig. $2 ; \mathrm{H}$. g. o.), just anterior to the ctenidium, so that it extends forward to the male genital orifice near the mouth. The seminal groove is low and very narrow.

The parapodia are long, originating near the front of the cephalic shield and ex- 
tending posteriorly almost to the end of the tail. The highest part of the parapodia is at the anterior of the dorsal hump. There is no distinction between the parapodia and foot. With parapodia extended the animal is longer than it is wide.

The foot is narrow, slightly indented anteriorly, and can frequently be seen just anterior to the cephalic shield when the animal is crawling. The foot extends posteriorly to create a short, rounded tail (Text-fig. 1 ; T.). The slit from the pedal gland is extremely short and does not reach the end of the tail.

No shell has been found in $G$. brunneomarginatum. The radular formulae for ani-

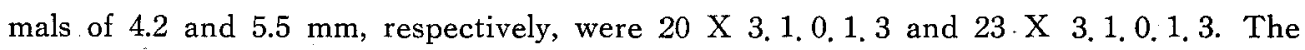
radula (Text-fig. 13. b) is small, about $0.22 \mathrm{~mm}$ long on a $4.2 \mathrm{~mm}$ animal and is very similar to that of G. flavum in having denticulations, about eight, along the edge of the first lateral. Although the teeth are very small they are very long for the small size of the radula. One of the main differences in the radulae of $G$. brunneomarginatum and $G$. flavum is that $G$. flavum has a wide flange on which the denticles are located, whereas G. brunneomarginatum has denticles on a very narrow flange (Text-figs. 13. a, b).

G. brunneomarginatum when first observed in its natural environment looks like G. flavum. Upon closer examination the two are distinctly different (see comparative dorsal drawings (Text-figs. 12. c, e)). The coloration is similar in that both are basically yellow animals with $G$. brunneomarginatum being transparent yellow with small regular yellow spots. G. brunneomarginatum has a broad chocolate brown band along the edge of the parapodia and brown on the upper part of the funnel and the dorsomedian crest. The flagellar appendage is brown and extending from it crossing to the left side is an irregular brown band. Some animals have a brown band outlining the extreme posterior of the dorsal hump. The ctenidium is transparent with some minute flecks of yellow.

REMARKS: All the specimens found in Guam waters have been taken from shallow depths on the reef flat to 4.5 meters, usually under rocks and coral rubble. G. brunneomarginatum also differs from G. flavum in ways other than external coloration. $G$. flavum has an extremely short free mantle margin located anteriorly on the dorsal hump and a short mammary protuberance on the posterior of the dorsal hump, whereas G. brunneomarginatum has a longer mantle margin extending back to a long flattened flagellar appendage. The general body shape is also quite different with $G$. brunneomarginatum having a much longer, narrower body and much longer parapodia. Although the teeth are similar they differ in that the denticles on the first lateral are on a wide flange in G. flavum and a very narrow one in G. brunneomarginatum.

The species name brunneomarginatum refers to the broad brown margin on the parapodia. 


\section{Gastropteron citrinum n. sp.}

(Text-figs. 3, 4, 12. d, 13. c; Pl. X, fig. 2)

DesCRIPTION: Over 400 specimens have been observed from Guam waters since March, 1970. Most were slightly over $3.0 \mathrm{~mm}$ in length.

The general body shape (Text-fig. 3 ) is the same as G. flavum. The body is elongate with a high, smooth, rounded dorsal hump, a cephalic shield with a high funnel, and a dorso-median crest which extends well beyond the funnel. G. citrinum has a lo long pointed posterior projection (Text-fig. 3,4 ; Pr.) rather than a mammary shaped

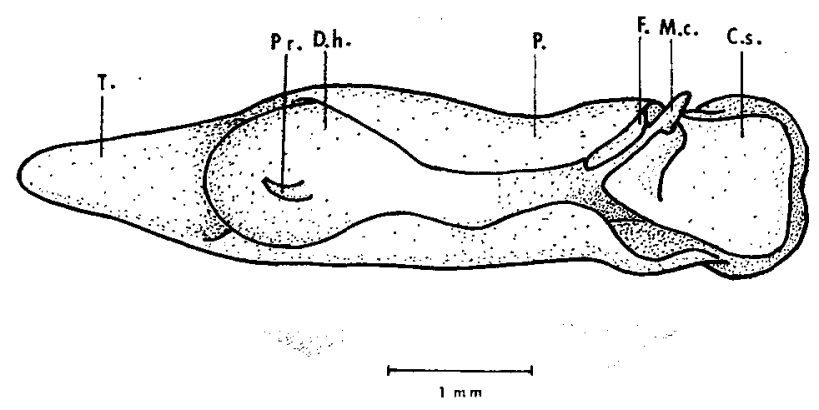

Text-fig. 3. Gastropteron citrinum n. sp. Dorsal view.

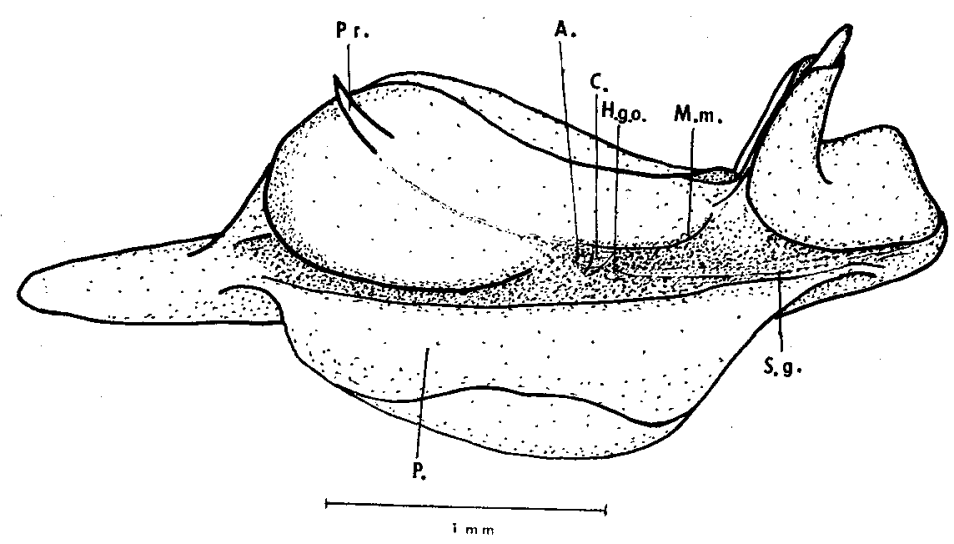

Text-fig. 4. Gastropteron citrinum n. sp. Right side view.

projection as on G. flavum. It also has longer parapodia and a slightly shorter tail (see comparative dorsal views (Text-fig. 12. d, e)).

On the living animal the free mantle margin (Text-fig. $4 ; \mathrm{M} . \mathrm{m}$.) appears to be very narrow, basically a thickened area of the epidermis, extending from the anterior of the dorsal hump back to the dorsal projection, becoming very thin posteriorly. On 
preserved animals the mantle margin appears narrow and very short, terminating just posterior to the ctenidium (Text-fig. 4 ; C.). The ctenidium is very poorly developed and appears to be a very small simple leaflet. The hermaphroditic genital orifice (Text-fig. $5 ; \mathrm{H}$. g. o.) is immediately anterior to and below the ctenidium. The anus (Text-fig. 4 ;A.) is posterior to the gill. The seminal groove (Text-fig. $4 ;$ S. g.) is distinct and very low. The pedal gland is located under the dorsal hump and the slit is quite far from the end of the tail.

No shells have been found in G. citrinum. The radula (Text-fig. 13. c) is very small with the length being $0.23 \mathrm{~mm}$ in a $3.2 \mathrm{~mm}$ animal. The radular formula of animals of $2.5,3.0$, and $3.2 \mathrm{~mm}$ was $18-19 \times 3.1 .0 .1$. 3. The first lateral has one well developed, though not pointed, nodule and a thickened area below it suggesting an undeveloped node. All marginals are simple.

To the naked eye specimens of G. citrinum appear either yellow or pink with a dark brown protuberance on the dorsal hump and a dark brown tip on the dorsomedian crest. Through the microscope animals are basically transparent. Some have a yellow-orange or pink internal coloration, whereas others are entirely yellow. Those with pink are spotted with minute pink spots on the parapodia but have a yellow head, tail and foot. When observed in situ, G. citrinum can easily be confused with G. flavum.

REMARKS: G. citrinum has been observed throughout the year usually in shallow water on the reef flats. It is most commonly found under or on the edges of rocks and coral rubble but has also been observed in beds of the algae Caulerpa. Although basically a shallow water animal, G. citrinum has been collected as deep as 10 meters. It is similar to G. flavum and G. brunneomarginatum in coloration. The greatest difference between G. citrinum and the other two is the teeth, with the latter two having denticulate teeth and the former having two nodules. As was true of G. flavum, G. citrinum has been rarely seen from August to October, 1973.

The specific name citrinum was chosen because of the yellow coloration.

\section{Gastropteron ladrones n. sp.}

(Text-figs. 5, 6, 12. b, 13. d; Pl. X, fig. 3)

DESCRIPTION : Forty nine specimens have been observed on Guam. Animals vary from 2.5 to $4.8 \mathrm{~mm}$ in length, most commonly being about $3.0 \mathrm{~mm}$.

The cephalic shield (Text-fig. 5 ; C. s.), when seen from a dorsal view, is long and narrow. It is slightly broadened anteriorly, somewhat indented, with no cephalic tentacles. The cephalic shield narrows slightly posteriorly and forms a high funnel (Textfig. $5 ;$ F.) which projects forward but does not extend beyond the anterior of the shield when the animal is crawling. The dorso-median crest (Text-fig. $5 ; \mathrm{M}$. c.) is long, extending well beyond the anterior edge of the funnel. It has a furrow in the 
posterior of the base. On a $4.8 \mathrm{~mm}$ animal the cephalic shield is $1.3 \mathrm{~mm}$ long with funnel projecting upward, $0.9 \mathrm{~mm}$ wide at the anterior and $0.6 \mathrm{~mm}$ wide posteriorly. The eyes are visible through the integument in the middle of the cephalic shield.

The dorsal hump (Text-fig. 5 ; D. h.) is very high, smooth, short, rounded rather than elongate, with a large long posterior projection (Text-fig. 5, 6; Pr.) located just to the right of the midline. The projection has a blunt point. There is a distinct division between the dorsal hump and tail with the ventral part joining the tail about

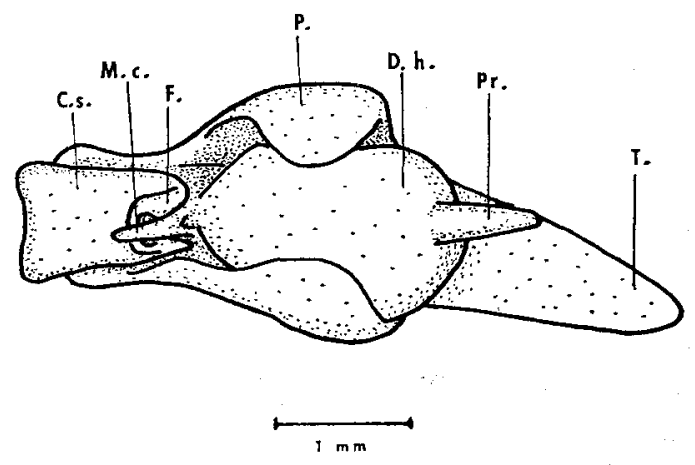

Text-fig. 5 Gastropteron ladrones n. sp. Dorsal view.

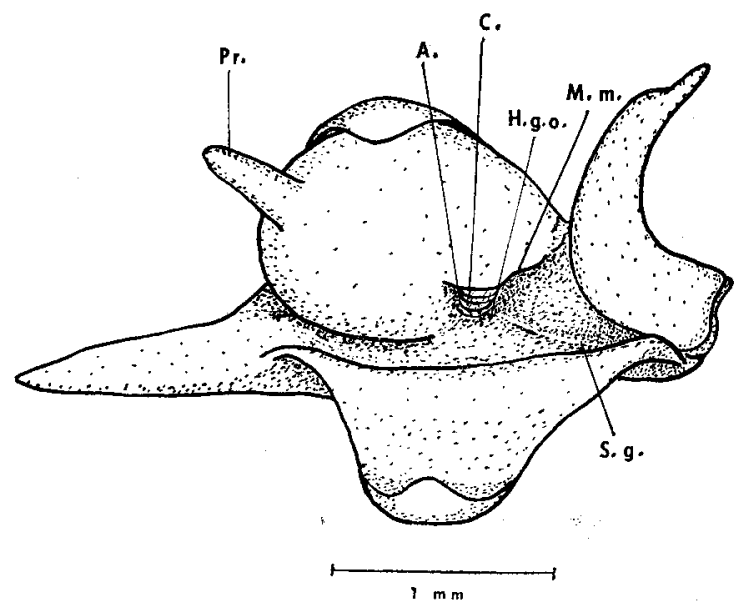

Text-fig. 6. Gastropteron ladrones n. sp. Right side view.

one third of the way from the anterior of the dorsal hump (see stylized drawing; Textfig. 11). On a $4.8 \mathrm{~mm}$ animal the dorsal hump is $2.0 \mathrm{~mm}$ long and about $1.3 \mathrm{~mm}$ wide. The free mantle margin (Text-fig. $6 ; \mathrm{M} . \mathrm{m}$.) is heavy, extremely short and originates near the right anterior of the dorsal hump, extending back only about one third of the length of the dorsal hump.

The ctenidium (Text-fig. $6 ;$ C.) is located below and at the anterior of the free 
mantle margin. It is very small, poorly developed and is hidden by the free mantle margin and the parapodia. It cannot be seen when the animal is crawling and is difficult to study even in a relaxed or preserved animal. The ctenidium is made up of four very small leaflets which are parallel to each other and to the free mantle margin. They are attached their entire length to the body. The anus (Text-fig. 6;A.) is located posterior to the ctenidium.

The seminal groove (Text-fig. 6; S. g.) is short and indistinct, running from the anterior of the most ventral leaflet in the ctenidium where the hermaphroditic genital orifice is located (Text-fig. $6 ; \mathrm{H}$. g. o.) to the male genital orifice near the mouth.

The parapodia (Text-fig. 5 ; P.) which begin about half way back on the head are short but very high. They extend posteriorly about two thirds of the length of the dorsal hump. They frequently meet middorsally and are capable of overlapping. A relaxed animal, with parapodia extended, is wider than it is long. Parapodia expand when the animal attempts to swim.

The foot is slightly indented anteriorly, long, and is not distinct from the parapodia. It extends posteriorly to form a very long tapered tail (Text-fig. $5 ; \mathrm{T}$.) which is almost one third of the body length. The pedal gland is easily visible from a ventral view but is hidden by a streak of color from a dorsal view.

No shell has been found in G. ladrones. The jaws are very poorly developed having sparce irregularly spaced rods of unequal lengths. The radula is very small with the ribbon being $0.18 \mathrm{~mm}$ long on a $3.8 \mathrm{~mm}$ animal. The radular formulas for animals of $2.5,3.8$, and $4.5 \mathrm{~mm}$ respectively were $17 \mathrm{X} 2.1 .0 .1 .2,19 \mathrm{X} 3.1 .0 .1 .3$, and $15 \mathrm{X} 2$. 1. 0.1.2. As in G. citrinum, the first lateral (Text-fig. 13. d) has a slight rounded nodule and a thickened area below on the inner edge suggesting another undeveloped node. The marginals are simple.

G. ladrones is very vividly and quite distinctly marked. The cephalic shield is yellow with an orange line down the center and orange lines on either side which join the central line anteriorly. The edges of the funnel are lined in orange as are several large white spots on the sides of the funnel. The dorsal hump is orange or yellow orange with large white spots. The parapodia are light brown with one very large yellowish white spot outlined in orange at the highest point. The anterior and posterior edges of the parapodia are lined in chocolate brown. The inside of the parapodia is whitish yellow. The tail is transparent, yellowish with a median yellow green line. The tail is edged with an orange line which continues forward along the base of the parapodia. The ctenidium is transparent.

REMARKS: $G$. ladrones has been observed in Bile Bay, near the village of Merizo, throughout the year. It has been found only in shallow water, usually on the reef flat or in a small boat channel which is no more than one meter deep. The animals have been observed breeding during the months of December and January, but no egg masses have been found which can definitely be attributed to them. Normally, the animals are found singly, at times in pairs, usually under or on the edges of rocks or 
coral rubble. The animals are generally rather lively in movement, moving with a jerking motion similar to that of many Sacoglossa. Animals have been observed swimming when brought into the laboratory but never in the ocean.

G. ladrones is quite different from the previously described Gastropteron in external body shape, as well as in coloration. It has a dorsal hump much shorter and rounder than that of the other species, shorter parapodia and a much longer tail and posterior projection (see comparative dorsal views; Text-fig. 12). The teeth closely resemble those of G. citrinum in having poorly developed nodules. The free mantle margin is very short like that of G. flavum. G. ladrones was also found to be rare from August to October, 1973.

The animal is called ladrones after an old Spanish name for the Mariana Islands.

\section{Genus Sagaminopteron}

Two species of Sagaminopteron have previously been described from Guam; S. nigropunctatum Carlson \& Hoff, 1973, and S. bilealbum Carlson \& Hoff, 1973. One additional species has been collected on Guam.

\section{Sagaminopteron psychedelicum n. sp.}

(Text-figs. 7, 8, 9. 10, 12. a, 13. e; Pl. X, fig. 4)

DESCRIPTION : Altogether, 31 specimens have been observed on Guam. Specimens vary from 2.4 to $12.7 \mathrm{~mm}$ in length, with the average being about $6.5 \mathrm{~mm}$. One 6.0 $\mathrm{mm}$ specimen was collected in Bandera Bay, Pagan, one of the northern Mariana Islands.

The cephalic shield (Text-fig. 7; C. s.), when seen from a dorsal view, is short, about one quarter of the length of the animal with the funnel raised. It is broadened anteriorly with anteriorly projecting cephalic tentacles (Text-fig. $7 ;$ C. t.) which are

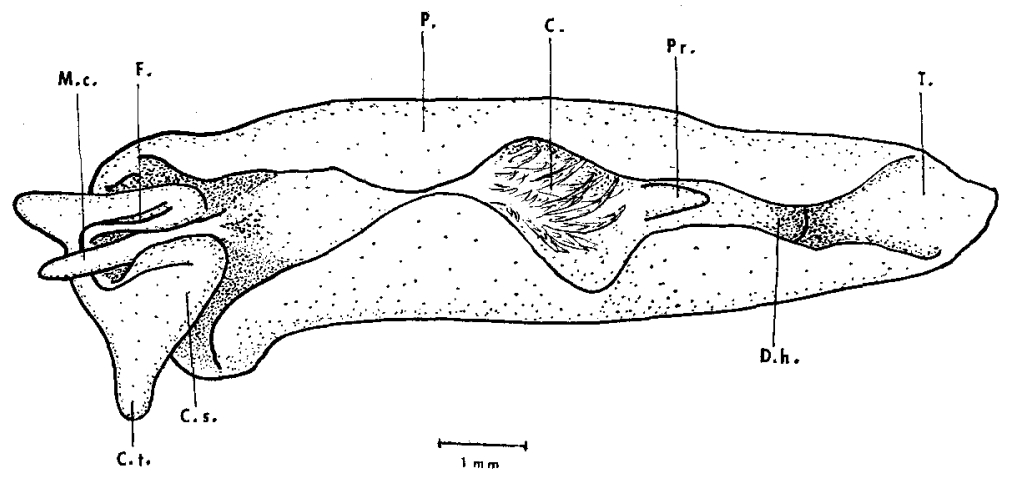

Text-fig. 7. Sagaminopteron psychedelicum n. sp. Dorsal view. 
longer than most Gastropteridae. The cephalic shield becomes very narrow posteriorly and forms a very long funnel (Text-fig. 7 ; F.) which is raised and normally projects well past the anterior limit of the head when seen from a dorsal view. The dorsomedian crest (Text-fig. 7; M. c.) is very long; extending through the center of and projecting well beyond the edge of the funnel. The funnel is very long, thin and the edges almost meet posteriorly so that the dorso-median crest is barely visible. The eyes can barely be seen through the integument on the head.

The dorsal hump (Text-fig. 7 ; D. h.) is high, rounded, elongate-oval and is distinctly separated from the tail (Text-fig. $7 ; \mathrm{T}$.). It is smooth, has one pointed projection (Text-figs. 7,$8 ; \mathrm{Pr}$.) on the mid dorsum and a bulge at the extreme posterior toward the right side. One $12.0 \mathrm{~mm}$ specimen was lacking the bulge but had 4 or 5 small bumps posteriorly and a few scattered irregularly over the dorsum. The free mantle margin (Text-figs. 8,$9 ;$ M. m.) is very short, originating anteriorly and extending

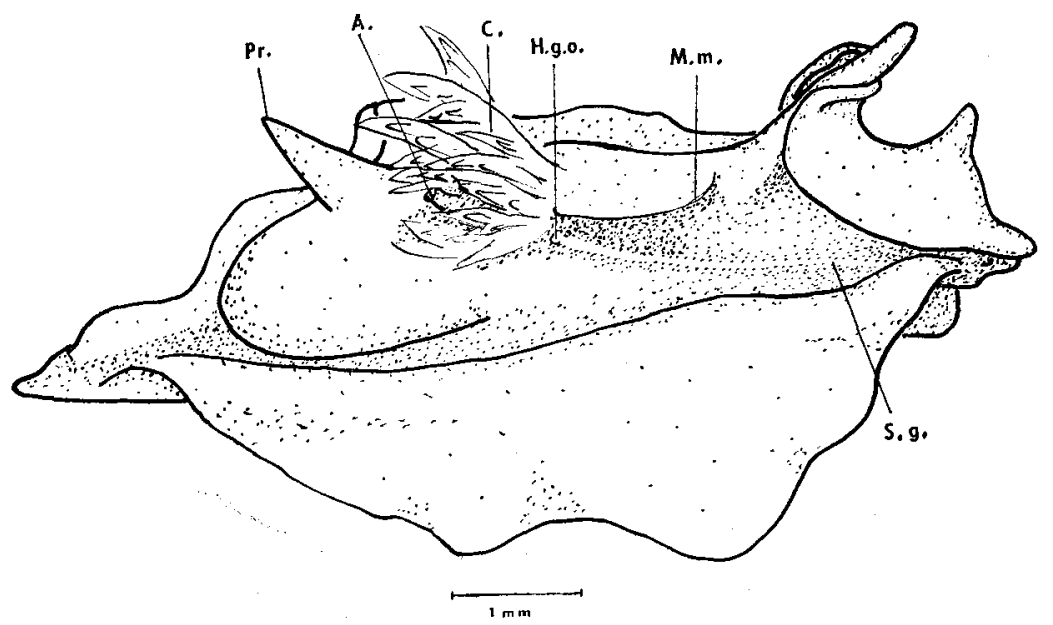

Text-fig. 8. Sagaminopteron psychedelicum n. sp. Right side view.

back about one third of the length of the dorsal hump. It is rather poorly developed being just a thickened part of the epidermis. The free mantle margin terminates anterior to the ctenidium. The posterior projection is not an extension of the free mantle margin as it frequently is in the Gastropteridae.

The ctenidium (Text-figs. 7, 8, 9;C.) is large, very well developed, easily visible from a dorsal view. There are 4 rachi extending from the mid dorsum to a sub medial position. The more ventral two appear to have a common rachis and are attached part of their length. The most ventral leaflet is the smallest. The more dorsal two are entirely free, project directly from the dorsal surface, and are branched. The middorsal gill has about 10 leaflets extending from the rachis with two of the middle pairs long. Each of the long pairs of leaflets have very small pinnae projecting from them. The next gill has eight leaflets with the distal four being long. The third gill has 9 leaflets 
with the mid three being long and containing pinnae. The last gill is also branched but not as well developed as the others. The anterior base of the most dorsal two gills has the same texture as the epidermis. The anal papillae (Text-fig. 8;A.) is very large, protruding just posterior to the ctenidium behind the third gill from the mid dorsum. The hermaphroditic genital orifice (Text-figs. 8,$9 ; \mathrm{H} . \mathrm{g}$. o.) is just below the termination of the free mantle margin at the base of the most ventral ctenidial leaflet. The seminal groove (Text-figs. 8,$9 ; \mathrm{S}$. g.) is easily visible on the living animal. It extends from the hermaphroditic genital orifice to the male genital orifice near the mouth.

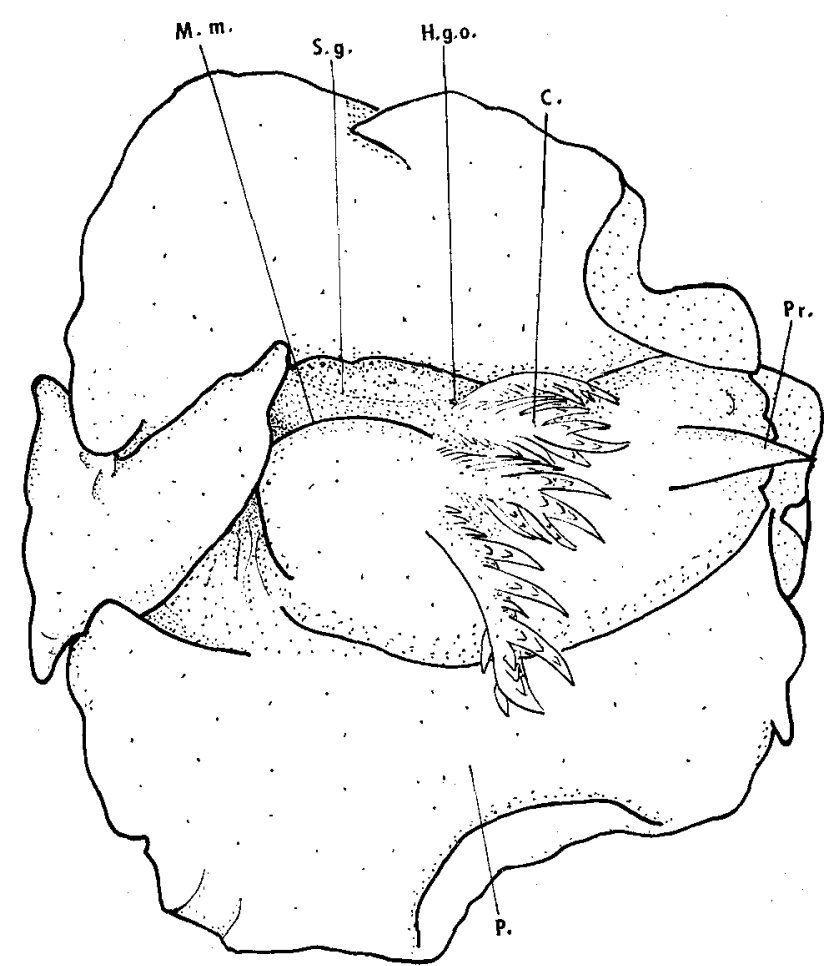

Text-fig. 9. Sagaminopteron psychedelicum n. sp. Relaxed animal.

The parapodia (Text-figs. 7, 9; P.) are very long, extending from near the anterior of the head almost to the end of the tail. They extend up the sides often beyond the height of the dorsal hump but do not normally extend across the dorsum. They are very broad. A relaxed animal is much broader than it is long. The edge of the parapodia is normally wavy. The animal extends the parapodia when swimming.

The foot is narrow and slightly idented anteriorly. There is no distinction between the foot and parapodia.

The tail is long, bluntly pointed but appears short because the parapodia extend 
almost to the posterior of the entire animal. There is no distinction between the foot and the tail. There is a groove extending from the pedal gland to near the end of the tail.

The shell (Text-fig. 10) is very small, occupying the area of the bulge at the posterior of the dorsal hump. The shell has grown from the veliger shell with obvious lines and a clear distinction between the new growth and the veliger shell. On 2.5 and $4.0 \mathrm{~mm}$ animals the shells were $0.75 \mathrm{X} 0.43 \mathrm{~mm}$ and $0.76 \times 0.42 \mathrm{~mm}$ respectively. No shells have been found in mature specimens.

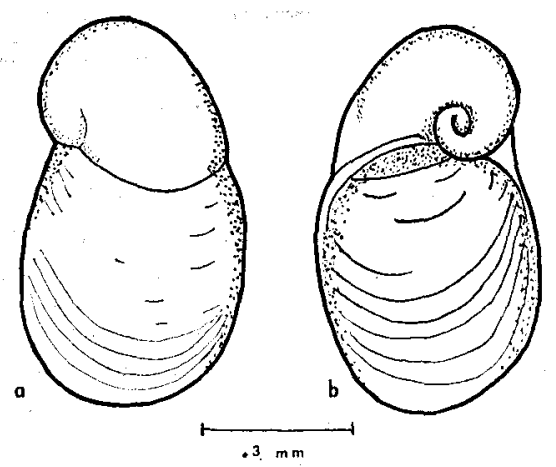

Text-fig. 10. Sagaminopteron psychedelicum n. sp. Shell.

a. Dorsal view, shell of $4.0 \mathrm{~mm}$ animal.

b. Ventral view, shell of $4.0 \mathrm{~mm}$ animal.

The radula is very large with the ribbon being $0.6 \mathrm{~mm}$ in a $12.0 \mathrm{~mm}$ animal. The jaws are yellowish brown, about $0.4 \mathrm{~mm}$ long in a $12.0 \mathrm{~mm}$ animal and are made up of rods. The radular formulas for five specimens are as follows:

$\begin{array}{rl}12.0 \mathrm{~mm} & 23 \times 12.1 .0 .1 .12 \\ 8.0 \mathrm{~mm} & 28 \times 10.1 .1 .10 \\ 6.0 \mathrm{~mm} & 27 \times 10.1 .0 .10 \\ 4.0 \mathrm{~mm} & 22 \times 9-10.1 .0 .1 .9-10 \\ 2.5 \mathrm{~mm} & 21 \times 9.1 .0 .1 .9\end{array}$

The radula (Text-fig. 13. e) matches the characteristics delineated by Tokioka and Baba (1964) for the Sagaminopteron in having two cusps on the inner edge of the main hook of the first lateral and in having more numerous marginals than the Gastropteron. The teeth are shaped like those of previously described Sagaminopteron except for the cusps on the first lateral. On the distal end of the radula the top most cusp is pointed but the lower one is more of a curved extension rather than being pointed. Both cusps are sharply pointed on the proximal end of the radula.

S. psychedelicum (Pl. X, Fig. 4) is quite complex in its markings. The base color of the head is light green with pale orange cephalic tentacles and several large medium orange to rust orange spots encircled by black lines. The tip of the dorso median crest is bright red-orange. The posterior of the crest has some black spots and irregular yellowish blotches. The dorsal hump is green with numerous large, irregularly. 
shaped orange spots surrounded by black lines. The projection has an orange spot at the base, the mid part is pale green and the tip pale orange. The parapodia are rimmed in light orange with an irregular black line beneath the orange. Irregular orange spots surrounded by black appear on the parapodia with the most ventral ones being elongate. The inside of the parapodia is greenish white with a few black spots. Orange spots appear on the tail but are paler than on the body. The foot is greenish white with one long orange spot outlined in black. The ctenidium is transparent with black flecks and a few yellowish blotches. The base of the most dorsal two has the same coloring as the dorsal hump.

Immature animals are basically white with orange spots outlined in black appearing only on the dorsal hump. The edge of the parapodia, the projection and the posterior of the funnel are pink. There is a black inverted ' $V$ ' posterior to the funnel.

REMARKS: S. psychedelicum has been found in Guam throughout the year on the reef flats and down to a depth of 10 meters. It is most frequently found between 3 and 5 meters. It has often been found on or near a grey sponge, Dysidea cf. reticulata (Thiele). Specimens are most frequently found singly. The animal is very active in crawling and is capable of swimming. When irritated, the animal emits a milky substance. No egg masses have been found which can definitely be attributed to $S$. psychedelicum. Animals brought into the laboratory have been observed mutually copulating by suspending themselves from a thread of mucous and assuming a head to tail position, thus creating a circle. No animals in situ have been observed breeding in this manner.

This species is named psychedelicum because of its extraordinary coloring.

\section{Comments}

Several of the species discussed, Gastropteron flavum, G. brunneomarginatum, and $G$. citrinum are very similar when observed in their natural environments. All are very small yellow animals. Externally G. flavum and G. citrinum are so similar that upon superficial examination one could be accepted as a slight variation of the other. On closer examination it can be seen that the mantle margin, length of parapodia, and posterior protuberance are quite different. Both G. brunneomarginatum and G. citrinum have mantle margins which extend from the anterior of the dorsal hump to the posterior projection, whereas G. flavum has an extremely short mantle margin which terminates just posterior to the ctenidium. G. brunneomarginatum has a much narrower and longer body and has long parapodia whereas the other two have shorter parapodia. The dorsal protuberance is different in the three species. G. flavum has a very small mammary-like knob, G. citrinum a long pointed projection, and G. brunneomarginatum a flattened flagellar appendage as a termination to the free mantle margin. The ctenidium in both G. flavum and G. citrinum is quite small and poorly developed, whereas $G$. brunneomarginatum has a much larger gill, though none of the three have 
a really well developed ctenidium. A noticeable internal difference between the three is the radula. G. flavum and G. brunneomarginatum both have denticulations on the inner edge of the first lateral; however the radula of $G$. brunneomarginatum has much longer teeth in relation to the length of the radula than G. flavum and the denticles of $G$. flavum are on the edge of a very wide flange in comparison to a narrow flange in G. brunneomarginatum. G. citrinum has no denticulations but rather has one fairly strong nodule and one poorly developed node below it. All three have only 2 or 3 marginals on a side.
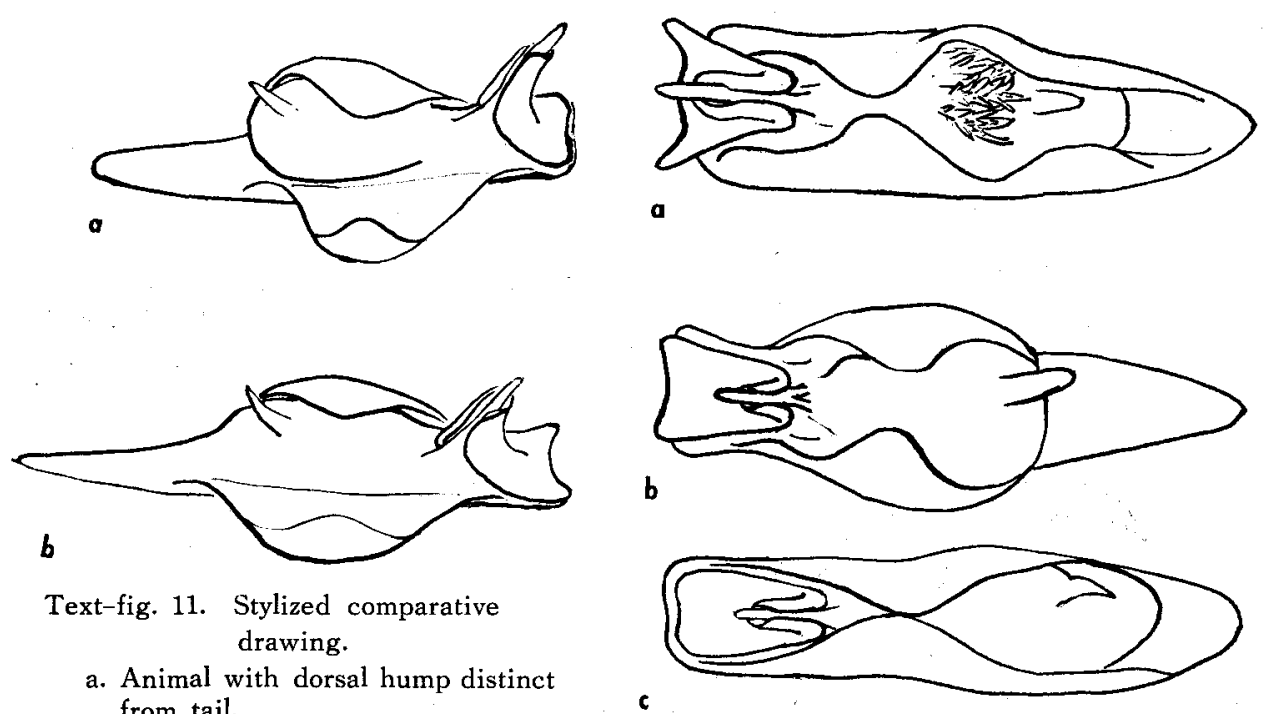

a. Animal with dorsal hump distinct from tail.

c

b. Animal with dorsal hump slanting to tail.

Text-fig. 12. Comparative dorsal view.

a. Sagaminopteron psychedelicum n. sp.

b. Gastropteron ladrones n. sp.

c. Gastropteron brunneomarginatum n. sp.

d. Gastropteron citrinum n. sp.

e. Gastropteron flavum Tokioka and Baba, 1964.

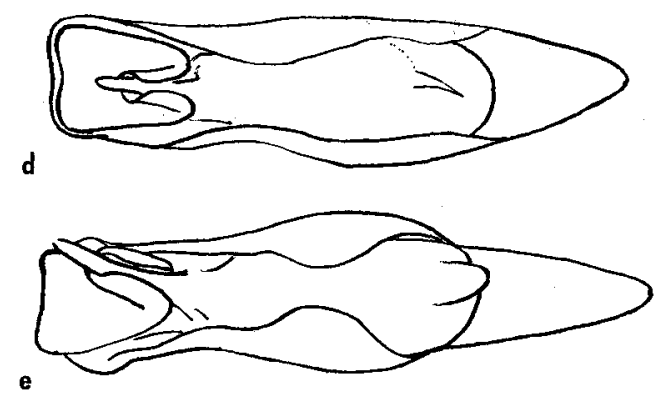

The radulae of $G$. citrinum and $G$. ladrones appear to be distinctly different from those of the other members of the Gastropteridae, with both having two nodules on the inner edge of the first lateral. The three genera that presently comprise the Gastropteridae were established primarily on the basis of the first lateral. Gastropteron have a first lateral with denticulations, exemplified by G. rubrum (Rafinesque, 1814), G. pacificum Bergh (1893), G. japonicum Tokioka \& Baba (1964), G. flavum Tokioka 
\& Baba (1964), G. viride Tokioka \& Baba (1964), G. bicornutum Baba \& Tokioka (1965); or have no denticulations, exemplified by G. sibogae Bergh (1905). The Sagaminopteron have two well defined cusps and more numerous marginals, such as S. ornatum Tokioka \& Baba (1964), S. bilealbum Carlson \& Hoff (1973) and S. nigropunctatum Carlson \& Hoff (1973). Enotepteron is a genus with 4 well defined cusps on the first lateral and few marginals, exemplified by Enotepteron. flavum Minichev (1967). Although the first lateral of G. citrinum and G. ladrones does not
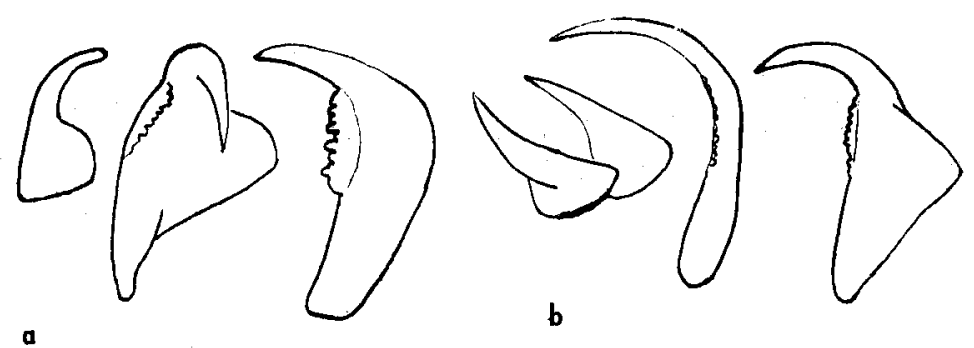

b
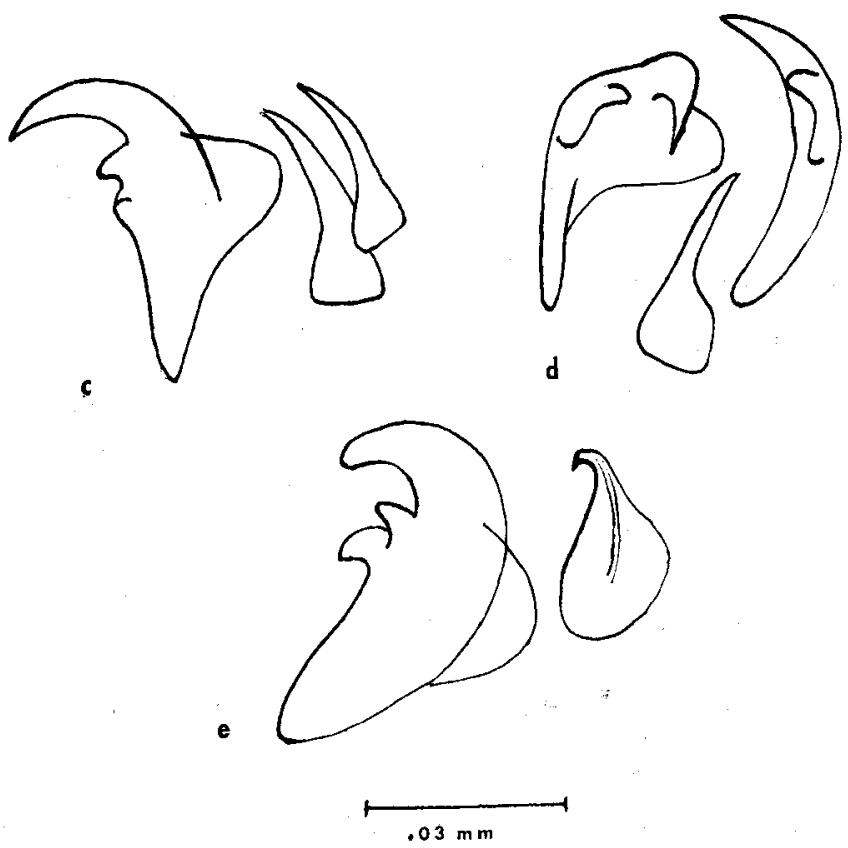

Text-fig. 13. Radular teeth. First lateral and marginals drawn to same scale.
a. Gastropteron flavum Tokioka and Baba. Teeth of $3.5 \mathrm{~mm}$ specimen
b. Gastropteron brunneomarginatum n. sp. Teeth of $4.2 \mathrm{~mm}$ specimen.
c. Gastropteron citrinum n. sp. Teeth of $3.2 \mathrm{~mm}$ specimen.
d. Gastropteron ladrones n. sp. Teeth of $3.8 \mathrm{~mm}$ specimen.
e. Sagaminopteron psychedelicum $\mathrm{n}$. sp. Teeth of $2.5 \mathrm{~mm}$ specimen. 
quite fit those in the established genera, these species have been provisionally placed in the Gastropteron. Factors influencing this placement are the number of marginals (2-3) and the environment in which they are found. The Sagaminopteron on Guam have generally been found associated with sponges, while the Gastropteron have been found under and around rocks and coral rubble. Once more comparative work has been done on all of the Gastropteridae it may be found that $G$. citrinum and $G$. ladrones should be placed in a separate genera.

Sagaminopteron psychedelicum, with 2 very prominent cusps on the first lateral and numerous marginals, according to Tokioka and Baba's criterion obviously belongs to the genus Sagaminopteron. However, the ctenidium on this species differs from all other Gastropteridae described in this paper and from any others known by the authors. The ctenidium is so well developed that it is reminiscent of the branchia of many dorids with at least part of the ctenidium located middorsally and with the leaflets being separate and not all attached to one basal rachis. The ctenidium is not under the free mantle margin, as it is in other Gastropteridae, but is dorso-posterior to it. S. psychedelicum can also be identified by its very brilliant coloration.

All of the new species described in this paper have the high, rounded, smooth dorsal humps which are not attached to the tail posteriorly. S. nigropunctatum and $S$. bilealbum previously described from Guam, are quite different in that the dorsal hump slants downward posteriorly and connects with the tail (Text-fig. 11).

\section{ABBREVIATIONS}

$\begin{array}{llll}\text { A. } & \text { Anus } & \text { M. c. } & \text { Dorso-median crest } \\ \text { C. } & \text { Ctenidium } & \text { M. m. } & \text { Free mantle margin } \\ \text { C. s. } & \text { Cephalic shield } & \text { P. } & \text { Parapodia } \\ \text { C. t. } & \text { Cephalic tentacle } & \text { Pr. } & \text { Projection } \\ \text { D. h. } & \text { Dorsal hump } & \text { S. } & \text { Shell } \\ \text { F. } & \text { Funnel } & \text { S. g. } & \text { Seminal groove } \\ \text { F. a. } & \text { Flagellar appendage } & \text { T. } & \text { Tail } \\ \text { H. g. o. } & \text { Hermaphroditic genital orifice } & & \end{array}$

\section{REFERENCES}

Baba, Kikutaro \& Takasi Tokioka, 1965. Two more new species of Gastropteron from Japan, with further notes on G. flavum T. \& B. (Gastropoda : Opisthobranchia). Publ. Seto Mar. Biol. Lab., XII (5), pp. 363-378, text-figs. 1-8, plate XXV.

Bergh, R. 1893. Die Gattung Gastropteron. Zool. Jahrb., Abt. Anatomic u. Ontogenie, Vol. 7, Part 2, pp. 281-308, pls. $16-17$.

-_- 1905. Die Opisthobranchiata der Siboga-Expedition. Siboga-Exped., Monogr. 50.

Carlson, C. H., \& P. J. Hoff, 1973. Two new species of Gastropteridae from Guam, Marianas Islands (Opisthobranchia : Cephalaspidea). Publ. Seto Mar. Biol. Lab., vol. XXI, no. 2, pp. 141-151, Pl. 
IX, text-figs. $1-8$.

Minichev, Yu S., 1967. Studies on the morphology of the lower Opisthobranchia. On the evolutionary significance of the detorsion process. Akad. Nauk. Leningrad, Trudy Zoolog. Inst. V. 44, pp. 109-182, figs. 1-46. [Only section on Enotepteron flavum seen].

Tokioka, T., and K. Baba, 1964. Four new species and a new genus of the family Gastropteridae from Japan (Gastropoda: Opisthobranchia). Publ. Seto Mar. Biol. Lab., vol. 12, no. 3, pp. 201229 , pls. 10-13, text-figs. 1-15. 


\section{EXPLANATION OF PLATE $\mathrm{X}$}

Fig. 1. Gastropteron brunneomarginatum n. sp.

Fig. 2. Gastropteron citrinum $\mathbf{n}$. sp.

Fig. 3. Gastropteron ladrones n. sp.

Fig. 4. Sagaminopteron psychedelicum n. sp. 
Publ. Seto Mar. Biol. Lab., XXI (5/6), 1974.

PLATE X
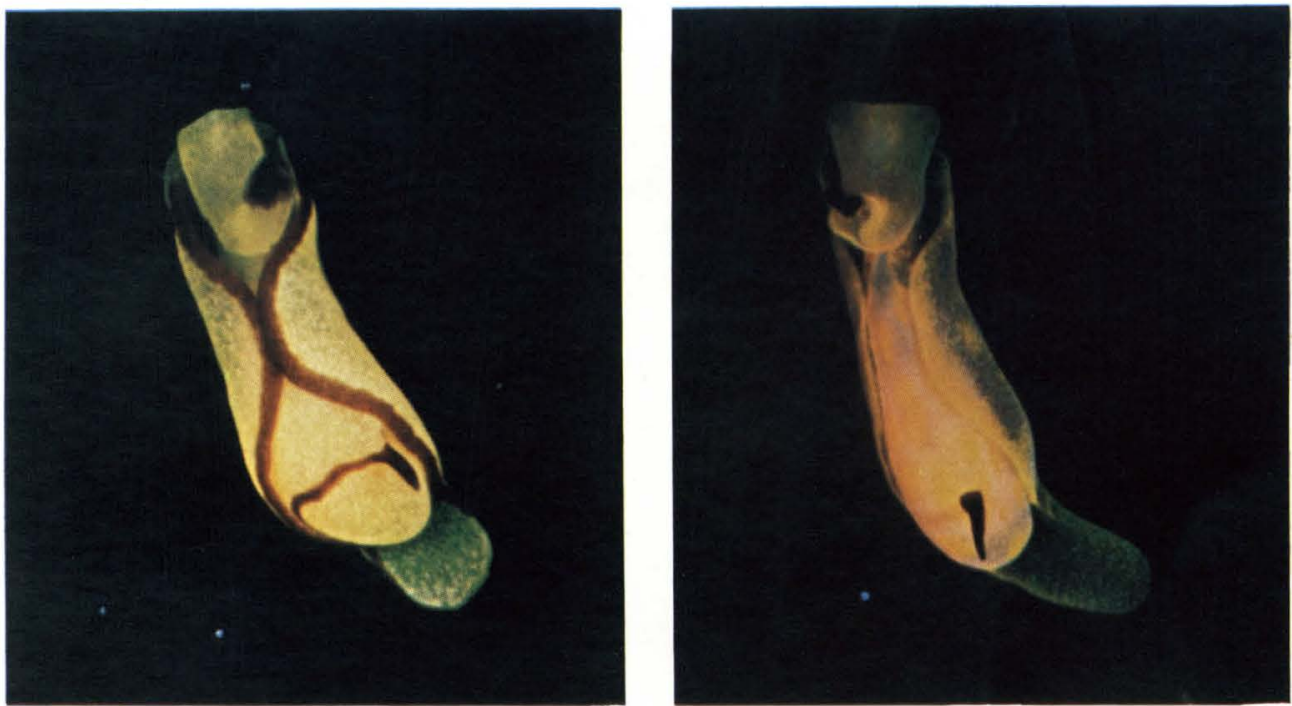

1

2

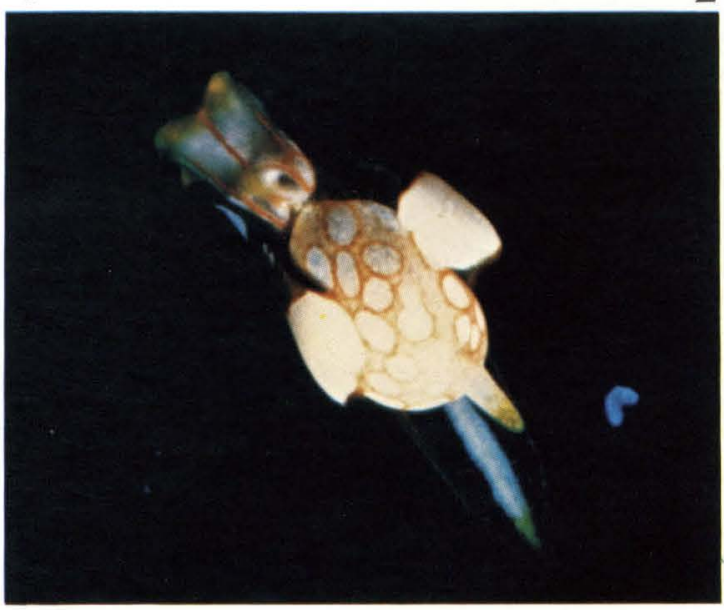

3

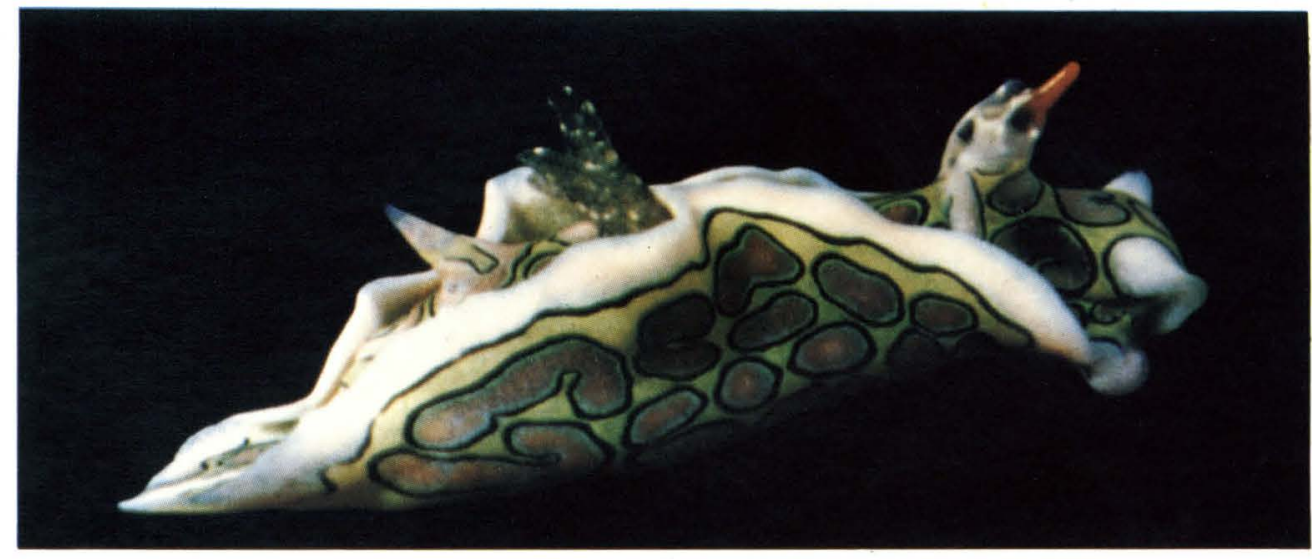

4

C.H. Carlson \& P.J. Hoff : The Gastropteridae of Guam 